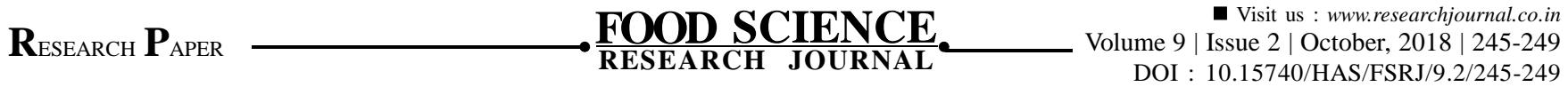

\title{
Acceptability of incorporation of jackfruit seed flour in cakes
}

\author{
C. Lalchhandami, Ch. Nganthoibi and $\mathrm{N}_{\text {atasha }} \mathrm{R}$. Marak
}

This study was conducted to determine the influence of incorporation of jackfruit seed flour in cakes. Jackfruit being abundantly available in Meghalaya during the spring-summer season is one of the most popular fruit in the state. However, the seeds often tend to be discarded or underutilised. Incorporation of jackfruit seed flour in recipes such as cakes will serve as a rich source of protein, starch and dietary fibres and can also be regarded as an abundant yet cheap source of the said nutrients. The seeds of mature, unripe jackfruit were used for making the cakes. Three variations of cakes with the incorporation of different amounts of the seed flour i.e., 20 per cent, 30 per cent and 40 per cent by replacing refined wheat flour were compared with a control. The cakes were evaluated on their sensory characteristics i.e., colour, appearance, texture, taste, aroma and overall acceptability. It was observed that incorporation of the seed flour at 30 per cent was the most acceptable with no affect on the sensory characteristics. It was concluded that refined wheat flour can be substituted with jackfruit seed flour at 30 per cent in preparation of cakes.

Key Words : Enriched cakes, Jackfruit seed flour, Seed flour utilization

How to cite this article : Lalchhandami, C., Nganthoibi, Ch. and Marak, Natasha R. (2018). Acceptability of incorporation of jackfruit seed flour in cakes. Food Sci. Res. J., 9(2): 245-249, DOI : 10.15740/HAS/FSRJ/9.2/245-249. Copyright@ 2018: Hind AgriHorticultural Society.

Author for correspondence :

C. Lalchhandami, Department of Food and Nutrition, College of Home Science, Central Agricultural University, Sangsanggre, Tura (Meghalaya) India (Email : clalchhandami1338@gmail.com)

Associate Authors' :

Ch. Nganthoibi and Natasha R. Marak, Department of Food Science and Nutrition, College of Home Science, Central Agricultural University, Sangsanggre, Tura (Meghalaya) India

(Email : singhpapak9642@gmail.com; natasha.marak@gmail.com) 